\title{
The Response of Electronic And Energetic Properties of Two Types of The Sp-hybridised Carbon-Carbon Bonds To An External Uniform Electric Field
}

\section{Nina Sadlej-Sosnowska}

National Medicines Institute: Narodowy Instytut Lekow

Agnieszka Ocios-Bębenek

National Medicines Institute: Narodowy Instytut Lekow

Dariusz Boczar ( $\nabla$ d.boczar@nil.gov.pl )

National Medicines Institute: Narodowy Instytut Lekow https://orcid.org/0000-0002-1881-7356

\section{Research Article}

Keywords: electric field, (10)cumulenes, (10)polyynes, polarizability

Posted Date: September 3rd, 2021

DOl: https://doi.org/10.21203/rs.3.rs-851343/v1

License: (c) (i) This work is licensed under a Creative Commons Attribution 4.0 International License.

Read Full License 


\section{Abstract}

The susceptibility of electronic and energetic properties of two sets of molecules to perturbation in a uniform electric field was investigated. The molecules of one set were (10)cumulenes terminated with two functional groups, $R_{1}$ and $R_{2}$; those of the second set were (10)polyyenes substituted with the same $R_{1}$ and $R_{2}$ groups. The cumulene and polyyne molecules had similar lengths of the system of conjugated bonds between the two most extreme carbon atoms. Dipole moments and polarizabilities of the molecules were used as determinants of the overall charge transfer between polar groups and their modifications due to the application of an external electric field. The field was directed along the main (longest) axis of the molecules from the negative to the positive pole. Comparison of the polarizability values revealed that they were higher in the (10)cumulenes than in the (10)polyynes. Parabolic dependence of the molecular energy as function of field strength can be interpreted in terms of the response of electron density to an electric field.

\section{Introduction}

Electric fields affect chemical reactions as the field can significantly alter the potential energy curves near the transition state region governing chemical reactions [1] and consequently, influence course and rate constants of the reactions. This way fields may also impact the biological properties of cells and their components. Impact of the external electric fields on diatomic molecules: energies, geometries, and vibrational Stark shifts is described by Sowlati-Hashjin and Matta [1]. These effects of the electric field were investigated both theoretically and experimentally. A comprehensive and informative review of structure and reactivity control has been written by Shaik et al. [2]. Most effects can be comprehended as field-augmented transition state stabilisation by ionic structures [2]. The interaction of molecules with external fields may result in the breaking and making of chemical bonds.

Upon variation of electric field and polarity, it is possible to stabilise different tautomeric forms of a molecule [3]. An electric field may also perturb molecular vibrations; the largest change in the IR spectrum induced by the field is a linear frequency shift [4]. There are many other reports describing the impact of electric field on the properties and reactivity of molecules [5-10].

This study is a continuation of the previous work [5] where the susceptibility of two other sets of molecules to perturbation in a uniform electric field was investigated. The molecules of one set were deca-1,3,5,7-pentaenes terminated with two functional groups, $R_{1}$ and $R_{2}$; those of the second set were 4$\mathrm{R}_{1}-4^{\prime}-\mathrm{R}_{2}-\mathrm{p}$-diphenylbenzenes, with $\mathrm{R}_{1}$ and $\mathrm{R}_{2}$ being the same as in the pentanes set. Comparison of the effect of the charge relocations in both series of the conjugated molecules revealed that the charge transfer imposed by the electric field was more efficient in the pentanes than in the aromatic compounds. From the point of view of this study, the most interesting papers are those dealing with molecules containing chains of carbon atoms [11-13]. Action of an electric field on atoms or molecules [14-18] can be measured and visualised with polarizability, resulting from the interaction of atoms or molecules with the field of their interaction or an atom or molecule in electric field. This computational study aims at 
gaining insight into the effect of external fields in two groups of molecules: polyynes and cumulenes with the same substituent pairs (Fig. 1). The examined cumulenes belong to class of even cumulenes, i.e. with an even number of cumulated double bonds [11].

Dipole moments were used as a measure of the overall charge transfer within the molecules, as in the case of deca-1,3,5,7-pentaenes and 4- $\mathrm{R}_{1}-4^{\prime}-\mathrm{R}_{2}$-p-diphenylbenzenes groups. Thus, the links (linkers) connecting substituents were chains of ten $s p$-hybridised carbon atoms. In molecules of one type, known as cumulenes, the carbon atoms are connected with double bonds, whereas in molecules of the second type, named polyynes, there are alternating single and triple bonds. Due to polar substituents, all molecules of both types are polarised and their energies depend on the applied field intensity. The polarizability values were calculated as slopes of the plots:

$\mathrm{d} E_{n} / \mathrm{d} F \mathrm{vs} F,(1)$

where $E_{n}$ stands for the energy of a molecule in an electric field and $F$ stands for the intensity of the applied field.

Polarizability is believed to play an important role in intermolecular interactions of heterogenous media such as protein-ligand binding. The methods of calculation of molecular dipole moments and polarizabilities was benchmarked [18].

Electron transmission through molecules and molecular interfaces has been a subject of intensive research due to a recent interest in electron transfer phenomena underlying the operation of the scanningtunnelling microscope on one hand and in the transmission properties of molecular bridges between conducting leads on the other [19]. Most electric field effects on molecular structures and reactions can be comprehended as the field-induced stabilisation of ionic structures.

\section{Calculation}

Molecular geometries were optimised with and without external fields. All calculations were conducted using the Gaussian 09 program [20]. The calculations were conducted using Lee-Yang-Parr correlation functional $\{B 3 L Y P\}[21]$. The $6-31+G\{d\}$ basis set with the polarised and diffusion functions was employed. The values of the electric field strength used in our calculation were taken from the interval 0.015 to 0.015 a.u. $\left(-7.71 \times 10^{9} \mathrm{~V} / \mathrm{m}\right.$ to $\left.+7.71 \times 10^{9} \mathrm{~V} / \mathrm{m}\right)$. The fields were applied along the $x$-axis of the coordinate system. The $\mathrm{C}-\mathrm{C}$ chains were approximately parallel to the $x$-axis of the coordinate system therefore all fields in this study have the same direction as the $x$-axis along which they are aligned (Fig. 1).

The axes were oriented so that the dipole moments of all molecules without any applied electric field were positive - that is, the dipole moments originate at the negative pole and point to the positive pole. Plots of the calculated energies against the field intensity $(F)$ are shown for (10)cumulenes in Fig. 2 and for (10) polyynes in Fig. 3 with the $\mathrm{NO}_{2}$ and $\mathrm{CN}$ substituents. Molecular polarizabilities were eventually 
obtained as slope values of the numerical derivatives of the calculated energies with respect to the applied field (Figs. 2b and 3b). Evaluation of a range of density functional theory (DFT) methods and basis sets used to calculations using Hartree-Fock theory is provided by Hickey and Rowley [18].

\section{Results And Discussion}

\subsection{Comparison of polarizabilities of the cumulenes and polyynes chains connecting the same substituents.}

Energies of the eight investigated systems (four cumulenes and four polyynes with different $R_{1}$ and $R_{2}$ substituents) were plotted as functions of the intensities of the applied field. These functions were represented as practically perfect parabolas, with coefficients of determination in the $0.999-1.000$ limits. Two examples of this plot are shown in Fig. 2a for (10)cumulene and in Fig. 3a for (10)polyyne bearing the same substituents, $\mathrm{NO}_{2}$ and $\mathrm{CN}$. The functions of energy $\left(E_{n}\right)$ against the electric field strength $(F)$ may be expressed by following quadratic Eq. (2), which is correct in the case where the fields that are colinear with the molecular axis were applied and higher terms in $F$ may be neglected [22]. Figures $2 a$ and 3a display energies of cumulenes and polyynes as functions of the strength of the electric field:

$E_{n}=E_{o}+\mu_{o} F-1 / 2 a F^{2}(2)$

In Eq. (2), $\mu_{o}$ is a dipole moment of a neutral molecule without the applied field and $a$ denotes molecular polarizability, a value which is a measure of the energy increment due to the dislocation of electron density within the molecule under the action of the electric field.

Based on Eq. (2), one may determine the dipole moment of the molecule without the field $\left(\mu_{o}\right)$ and in the field $(\mu(F))$ using the following equations:

$\mathrm{d} E_{n} / \mathrm{d} F=\mu_{o}-a F(3)$

$\mu(F)=\mu_{o}+a F(4)$

In a case where Eq. (3) is valid, the plot of $\mathrm{d} E_{n} / \mathrm{d} F$ against $F$ should be a straight line with a slope equal to $a$ and an intercept equal to the field-free dipole moment $\mu_{o}$. Such plots are shown in Figs. $2 \mathrm{~b}$ and $3 \mathrm{~b}$, for the cumulene and polyyne molecules with $\mathrm{NO}_{2}$ and $\mathrm{CN}$ substituents. The same calculations were performed for another cumulenes and polyynes with different substituents $\mathrm{R}_{1}$ and $\mathrm{R}_{2}$ such as $\mathrm{NO}_{2}, \mathrm{NH}_{2}$, $\mathrm{OH}, \mathrm{CN}$. It should be emphasised that the coefficients of determination of $\mathrm{d} E_{n} / \mathrm{d} F$ against $F$ for all eight molecules are 1 up to four decimals. Dipole moments of the molecules in the electric field directed along the x-axis, as shown in Fig. 1, were determined according to Eq. (4). As can be seen, dipole moments in the electric field directed along the $x$-axis of the molecules are larger for substituted cumulenes (Tables 1 ) than for polyynes (Table 2). 
Table 1

Dipole moments of the (10)cumulenes with two substituents, $R_{1}$ and $\mathrm{R}_{2}$

\begin{tabular}{|lllll|}
\hline F (atomic units) & $\mathbf{R}_{\mathbf{1}}=\mathbf{N O}_{\mathbf{2}}$ & $\mathbf{R}_{\mathbf{1}}=\mathbf{N O}_{\mathbf{2}}$ & $\mathbf{R}_{\mathbf{1}}=\mathbf{N O}_{\mathbf{2}}$ & $\mathbf{R}_{\mathbf{1}}=\mathbf{O H}$ \\
& $\mathbf{R}_{\mathbf{2}}=\mathbf{C N}$ & $\mathbf{R}_{\mathbf{2}}=\mathbf{N H}_{\mathbf{2}}$ & $\mathbf{R}_{\mathbf{2}}=\mathbf{O H}$ & $\mathbf{R}_{\mathbf{2}}=\mathbf{N H}_{\mathbf{2}}$ \\
\hline-0.015 & 17.5 & 23.9 & 21.1 & 17.0 \\
\hline 0 & 1.01 & 6.40 & 4.92 & 1.79 \\
\hline 0.015 & -15.6 & -11.1 & -11.3 & -13.4 \\
\hline
\end{tabular}

Table 2

Dipole moments of the (10)polyynes with two substituents, $R_{1}$ and

\begin{tabular}{|c|c|c|c|c|}
\hline \multicolumn{5}{|c|}{$\mathrm{R}_{2}$} \\
\hline F (atomic units) & $\mathrm{R}_{1}=\mathrm{NO}_{2}$ & $\mathrm{R}_{1}=\mathrm{NO}_{2}$ & $\mathrm{R}_{1}=\mathrm{NO}_{2}$ & $\mathrm{R}_{1}=\mathrm{OH}$ \\
\hline & $\mathrm{R}_{2}=\mathrm{CN}$ & $\mathrm{R}_{2}=\mathrm{NH}_{2}$ & $\mathrm{R}_{2}=\mathrm{OH}$ & $\mathrm{R}_{2}=\mathrm{NH}_{2}$ \\
\hline-0.015 & 11.81 & 20.66 & 18.24 & 14.3 \\
\hline 0 & 0.34 & 6.11 & 4.72 & 1.24 \\
\hline 0.015 & -11.13 & -8.44 & -8.81 & -16.74 \\
\hline
\end{tabular}

Electric dipole moment atomic unit is $\mathrm{e} \mathrm{a}_{\mathrm{o}}$ where $\mathrm{e}-$ is electron charge and $\mathrm{a}_{\mathrm{o}}-\mathrm{Bohr}$ radius. The electric dipole moment atomic unit equals $8.478 \times 10^{-30} \mathrm{C} \times \mathrm{m}$ or $2.542 \mathrm{D}$ (debye).

Polarizabilities of the substituted cumulenes and polyynes, obtained from the derivative of the electronic energy $\left(E_{n}\right)$ with respect to $F$, are given in Table 3 . The data show that polarizability values of cumulenes are $7-25 \%$ higher than those of polyynes.

Table 3

Polarizability of substituted cumulenes and polyynes in atomic units

\begin{tabular}{|lllll|}
\hline & $\mathbf{R}_{\mathbf{1}}=\mathbf{N O}_{\mathbf{2}}$ & $\mathbf{R}_{\mathbf{1}}=\mathbf{N O}_{\mathbf{2}}$ & $\mathbf{R}_{\mathbf{1}}=\mathbf{N O}_{\mathbf{2}}$ & $\mathbf{R}_{\mathbf{1}}=\mathbf{O H}$ \\
& $\mathbf{R}_{\mathbf{2}}=\mathbf{C N}$ & $\mathbf{R}_{\mathbf{2}}=\mathbf{N H}_{\mathbf{2}}$ & $\mathbf{R}_{\mathbf{2}}=\mathbf{O H}$ & $\mathbf{R}_{\mathbf{2}}=\mathbf{N H}_{\mathbf{2}}$ \\
\hline (10)cumulene- $\mathrm{R}_{1} \mathrm{R}_{2}$ & -1102 & -1167 & -1122 & -1011 \\
\hline (10)polyyne- $\mathrm{R}_{1} \mathrm{R}_{2}$ & -975 & -970 & -901 & -949 \\
\hline
\end{tabular}

Polarizability atomic unit is $\mathrm{e}^{2} \mathrm{a}_{\mathrm{o}}^{2} / \mathrm{E}_{h}$, where $\mathrm{e}-$ is electron charge, $\mathrm{a}_{\mathrm{o}}-$ Bohr radius, and $E_{h}-$ hartree. The polarizability atomic unit equals $1.649 \times 10^{-41} \mathrm{C}^{2} \mathrm{~m}^{2} / \mathrm{J}$.

3.2.Comparison of two types of the sp-hybridised carbon-carbon double bonds. 
Figure 1 shows that the carbon atoms are linked by double bonds in cumulenes, whereas in polyynes there are alternating single and triple bonds. To verify this structure, we compared bond length values for two series of molecules with the same functional groups without the applied electric field and with the field of intensities +0.01 and -0.01 a.u. The data is shown in Table 4 .

Table 4

Comparison of mean bond lengths of the $\mathrm{C}$ - $\mathrm{C}$ bonds in 10 -cumulene- $\mathrm{NO}_{2} \mathrm{CN}$ and 10 polyyne- $\mathrm{NO}_{2} \mathrm{CN}$ and their standard deviations

\begin{tabular}{|lllllll|}
\hline & \multicolumn{3}{l}{$\left(\mathbf{1 0}\right.$ cumulene- $\mathbf{R}_{\mathbf{1}} \mathbf{R}_{\mathbf{2}}$} & \multicolumn{3}{l|}{ (10)polyyne- $\mathbf{R}_{\mathbf{1}} \mathbf{R}_{\mathbf{2}}$} \\
\hline Field, a.u. & 0 & 0.01 & -0.01 & 0 & 0.01 & -0.01 \\
\hline Mean value of bond length & 1.29 & 1.29 & 1.30 & 1.28 & 1.28 & 1.28 \\
\hline SD of bond length & 0.024 & 0.024 & 0.029 & 0.050 & 0.050 & 0.045 \\
\hline
\end{tabular}

Data in Table 4 is evidence that the mean bond lengths of the link between two functional groups are nearly the same for the both types of the linker and do not change when the electric field (of the strength of +0.01 and -0.01 a.u.) is applied. These values (1.29 and $1.28 \AA$ ) can be compared with values of lengths of the single, double, and triple bonds calculated for the $\mathrm{CH}_{3}-\mathrm{CH}_{3}, \mathrm{CH}_{2}=\mathrm{CH}_{2}$, and $\mathrm{CH} \equiv \mathrm{CH}$ at the same calculation level (B3LYP/6-31+ $\left.G^{*}\right)$. The values were 1.53 (1.532), 1.34 (1.335), and 1.21 (1.2075) $\AA$, respectively. The comparison showed that the bonds in both types of molecules can be represented as double bonds with a small addition of triple bond. Cumulenes do not exhibit a substantial bond length alternation as compared with that of polyynes. Standard deviations of bond length for polyyne- $\mathrm{NO}_{2} \mathrm{CN}$ $(0.05 \AA)$ are twice as large as that for cumulene- $\mathrm{NO}_{2} \mathrm{CN}(0.02-0.03 \AA)$.

\section{Conclusions}

The reaction of cumulene and polyyne molecules with similar length of conjugation to electric field was compared. We report that polarizability of cumulenes is $7-25 \%$ higher than that of polyynes. Standard deviation of carbon-carbon bond length is twice as large in the group of polyynes as in the group of cumulenes. It turned out that the communication between two electroactive moieties (ending groups with varying degrees of polarity) connected to two different chains of the $s p$ carbon atoms is stronger in the group of cumulenes than in the group of polyynes.

\section{Declarations}

Funding The computing grant G44-18 from the Interdisciplinary Center for Mathematical and Computer Modelling (ICM) of Warsaw University and the financial support from the Polish Ministry of Science and Higher Education are gratefully acknowledged.

Conflicts of interest/Competing interests The authors declare no conflict of interest. 
Availability of data and material Data not available.

Code availability Not available.

Authors' contributions Conceptualization, methodology, formal analysis, writing-original draft preparation, N.S-S.; writing-review and editing, A.O-B. and D.B.; visualization, D.B. and A.O.-B. All authors have read and agreed to the published version of the manuscript.

Ethics approval Not applicable.

Consent to participate Not applicable.

Consent for publication Not applicable.

\section{References}

1. Sowlati-Hashjin S, Matta CF (2013) The chemical bond in external electric: Energies, geometries, and vibrational Stark shifts of diatomic molecules. J Chem Phys 139:144101. https://doi.org/10.1063/1.4820487

2. Shaik S, Ramanan R, Danovich D, Mandal D (2018) Structure and reactivity/selectivity control by oriented-external electric fields. Chem Soc Rev 47:5125-5145. https://doi.org/10.1039/C8CS00354H

3. Enchev V, Monev V, Markova N, Rogozherov M, Angelova S, Spassova M (2013) A model system with intramolecular hydrogen bonding: Effect of external electric field on the tautomeric conversion and electronic structures. Comp Theor Chem 1006:113-122. https://doi.org/10.1016/j.comptc.2012.11.021

4. Park ES, Boxer SG (2002) Origins of Sensitivity of Molecular Vibrations to Electric Fields: Carbonyl and Nitrosyl Stretches in Model Compounds and Proteins. J Phys Chem B 106:5800-5806. https://doi.org/10.1021/jp0203043

5. Sadlej-Sosnowska N (2019) The response of electronic and energetic properties of conjugated vs aromatic molecules to an external uniform electric field. Struct Chem 30:1407-1413. https://doi.org/10.1007/s11224-019-01345-6

6. Dominikowska J, Krygowski TM, Ozimiński WP, Palusiak M (2015) Aromaticity Induced by Electric Field: The Case of Polycalicenes. J Org Chem 80:9091-9101. https://doi.org/10.1021/acs.joc.5b01441

7. Dominikowska J, Palusiak M (2018) Tuning Aromaticity of para-Substituted Benzene Derivatives with an External Electric Field. ChemPhysChem 19(5):590-595.

https://doi.org/10.1002/cphc.201701203

8. Shaik S, de Visser SP, Kumar D (2004) External Electric Field Will Control the Selectivity of EnzymaticLike Bond Activations. J Am Chem Soc 126:11746-11749. https://doi.org/10.1021/ja047432k 
9. Ciampi S, Darwish N, Aitken HM, Diez-Pérez I, Coote ML (2018) Harnessing electrostatic catalysis in single molecule, electrochemical and chemical systems: a rapidly growing experimental tool box. Chem Soc Rev 47:5146-5164. https://doi.org/10.1039/C8CS00352A

10. Arabi AA, Matta CF (2011) Effects of external electric fields on double proton transfer kinetics in the formic acid dimer. Phys Chem Chem Phys 13:13738-13748. https://doi.org/10.1039/C1CP20175A

11. Garner MH, Bro-Jørgensen W, Pedersen PD, Solomon GC (2018) Reverse Bond-length Alternation in Cumulenes: Candidates for Increasing Electronic Transmission with Length. J Phys Chem C 122:26777-26789. https://doi.org/10.1021/acs.jpcc.8b05661

12. Milani A, Barbieri V, Facibeni A, Russo V, Li Bassi A, Lucotti A, Tommasini M, Tzirakis MD, Diederich F, Casari CS (2019) Structure Modulated Charge Transfer in Carbon Atomic Wires. Sci Rep 9:1648. https://doi.org/10.1038/s41598-018-38367-9

13. Gunasekaran S, Hernangómez-Pérez D, Davydenko I, Marder S, Evers F, Venkataraman L (2018) Near Length Independent Conductance in Polymethine Molecular Wires. Nano Lett 18:6387-6391. https://doi.org/10.1021/acs.nanolett.8b02743

14. Laidig KE, Bader RFW (1990) Properties of atoms in molecules: Atomic polarizabilities. J Chem Phys 93:7213-7224. https://doi.org/10.1063/1.459444

15. Truchon J-F, Nicholls A, Iftimie RI, Roux B, Bayly Cl (2008) Accurate Molecular Polarizabilities of Continuum Electrostatics. J Chem Theor Comput 4:1480-1493. https://doi.org/10.1021/ct800123c

16. Darling CL, Schlegel HB (1994) Dipole Moments, Polarizabilities, and Infrared Intensities Calculated with Electric Field Dependent Functions. J Phys Chem 98:5855-5861. https://doi.org/10.1021/j100074a008

17. Gough KM, Yacowar MM, Cleve RH, Dwyer JR (1996) Analysis of Molecular Polarizabilities and Polarizability Derivatives in $\mathrm{H}_{2}, \mathrm{~N}_{2}, \mathrm{~F}_{2}, \mathrm{CO}$, and $\mathrm{HF}$, with the Theory of Atoms in Molecules. Can $\mathrm{J}$ Chem 74:1139-1144. https://doi.org/10.1139/v96-128

18. Hickey AL, Rowley CN (2014) Benchmarking Quantum Chemical Methods for the Calculation of Molecular Dipole Moments and Polarizabilities. J Phys Chem A 118:3678-3687. https://doi.org/10.1021/jp502475e

19. Nitzan A (2001) Electron Transmission through Molecules and Molecular Interfaces. Ann Rev Phys Chem 52:681-750. https://doi.org/10.1146/annurev.physchem.52.1.681

20. Frisch MJ, Trucks GW, Schlegel HB, Scuseria GE, Robb MA, Cheeseman JR, Scalmani G, Barone V, Mennucci B, Petersson GA, Nakatsuji H, Caricato M, Li X, Hratchian HP, Izmaylov AF, Bloino J, Zheng G, Sonnenberg JL, Hada M, Ehara M, Toyota K, Fukuda R, Hasegawa J, Ishida M, Nakajima T, Honda Y, Kitao O, Nakai H, Vreven T, Montgomery JA Jr, Peralta JE, Ogliaro F, Bearpark M, Heyd JJ, Brothers E, Kudin KN, Staroverov VN, Keith T, Kobayashy R, Normand J, Raghavachari K, Rendell A, Burant JC, lyengar SS, Tomasi J, Cossi M, Rega N, Millam JM, Klene M, Knox JE, Cross JB, Bakken V, Adamo C, Jaramillo J, Gomperts R, Stratmann RE, Yazyev O, Austin AJ, Cammi R, Pomelli C, Ochterski JW, Martin RL, Morokuma K, Zakrzewski VG, Voth GA, Salvador P, Dannenberg JJ, Dapprich S, Daniels 
AD, Farkas O, Foresman JB, Ortiz JV, Cioslowski J, Fox DJ (2010) Gaussian 09, Revision D.01. Gaussian, Inc., Wallingford

21. Gill PMW, Johnson BG, Pople JA (1992) The Performance of the Becke-Lee-Yang-Parr (B-LYP) Density Functional Theory with Various Basis Sets. Chem Phys Lett 197(4-5):499-505. https://doi.org/10.1016/0009-2614(92)85807-M

22. De Biase PM, Doctorovich F, Murgida DH, Estrin DA (2007) Electric Field Effects on the Reactivity of Heme Model Systems. Chem Phys Lett 434:121-126. https://doi.org/10.1016/j.cplett.2006.11.104

Figures

$$
\begin{gathered}
\mathrm{R}_{1}-\mathrm{C} \equiv \mathrm{C}-\mathrm{C} \equiv \mathrm{C}-\mathrm{C} \equiv \mathrm{C}-\mathrm{C} \equiv \mathrm{C}-\mathrm{C} \equiv \mathrm{C}-\mathrm{R}_{2} \\
\text { polyyne }
\end{gathered}
$$

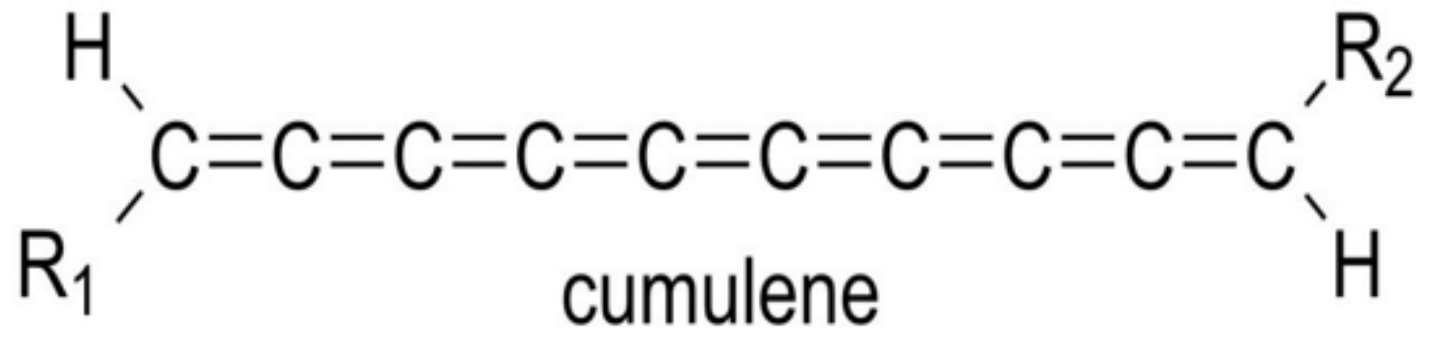

The electric field

\section{Figure 1}

Chemical structures of compared polyynes and cumulenes 

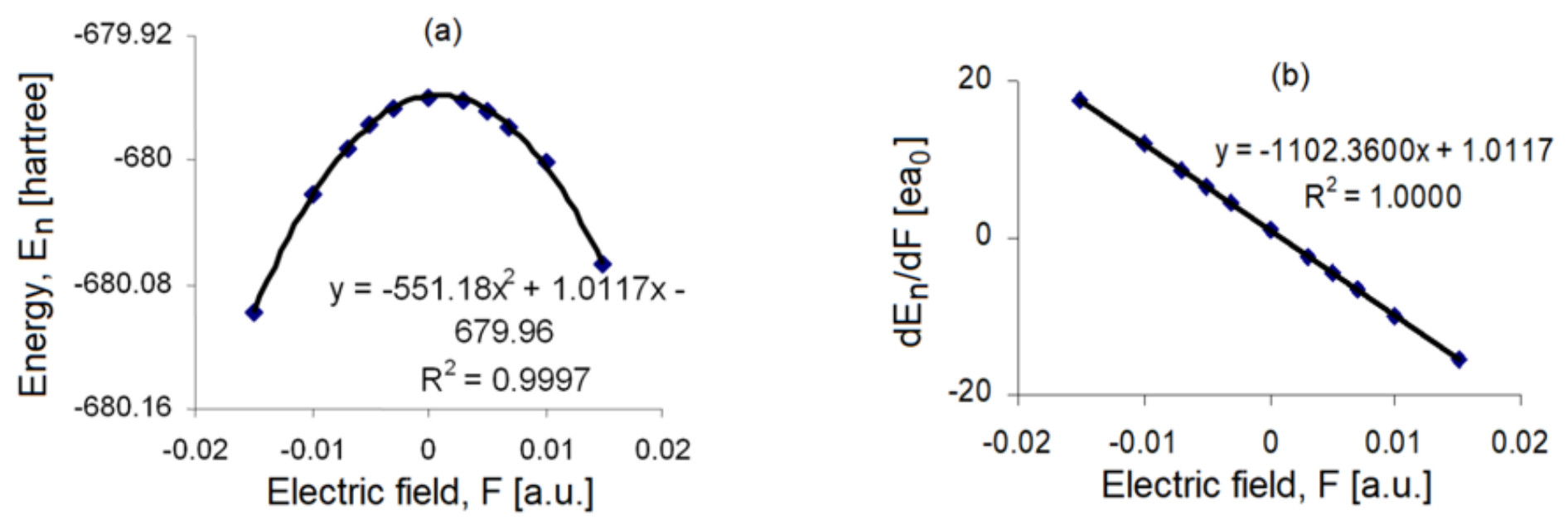

Figure 2

(a) Energy (En) of the (10)cumulene molecule with the NO2 and CN substituents as a function of the applied electric field (F) parallel to the molecular axis; (b) Plot of the derivative of energy of the (10)cumulene molecule with the NO2 and CN substituents with respect to $\mathrm{F}$
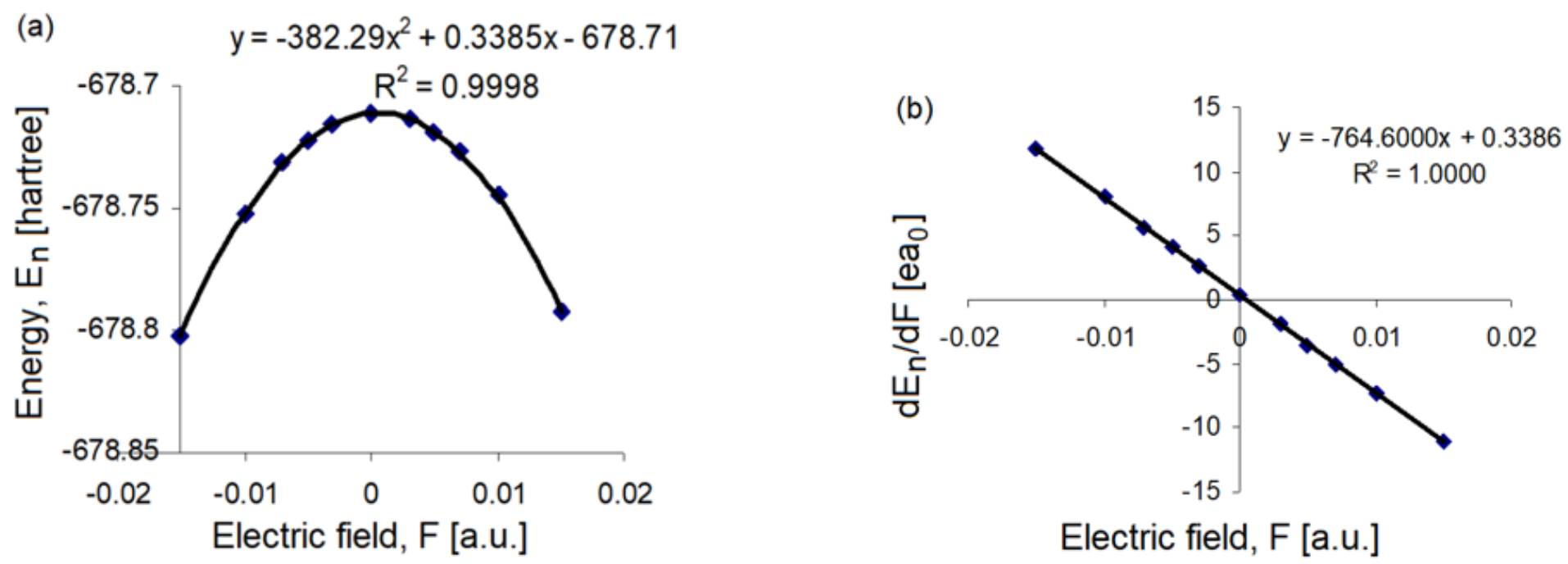

Electric field, $F$ [a.u.]

\section{Figure 3}

(a) Plot of En of the (10)polyyne molecule with the NO2 and CN substituents as a function of $\mathrm{F}$ in atomic units; (b) Plot of the derivative of energy of the (10)polyyne molecule with the NO2 and CN substituents with respect to $F$ 